\title{
TRATAMENTO DAS ESCARAS DE DECÚBITO COM PROPOLIS
}

\author{
Ivete Borsaro Soares de Azevedo1, Rosani Fernandes Sampaio1, Juan Cruz Montes2, Rabina- \\ dranth Loyola Leyela Contreras3.
} AZEVEDO, I. B. S. et alii. Tratamento das escaras de decúbi-
to com Própolis. Rev. Bras. Enf., Brasília, $39(2 / 3)$ : 33-37, abr./set., 1986.

\begin{abstract}
RESUMO. No presente trabalho, as autoras avaliam o uso do método natural da Própolis concentrada a 3\% (resina das plantas colhidas pelas abelhas passada pelo processo de digestão das mesmas liberando assim inúmeras enzimas enriquecendo o produto), em tratamento das escaras de decúbito. O trabalho consiste em: a) Preparar as escaras de decúbito para que, em tempo mais reduzido, sejam feitas as correções cirúrgicas e/ou curá-las em definitivo; b) Avaliar o poder bactericida e bacteriostático da Própolis. Deve-se ressaltar que o medicamento ativou consideravelmente a regeneração dos tecidos, reduzindo o tempo e o custo usuais para tratamento clássico das escaras de decúbito.
\end{abstract}

ABSTRACT. In this study the authors asses the natural method of $3 \%$ concentrated Propolis (resinuous plant substance enriched with varous enzimes by the bees' digestion process) in treating decubitus scabs. The work consists of a) preparing the scabs more quickly in order to make surgical corrections and/or heal them definetely; b) assessing its bactericidal and bacteriostatic power. It should be emphasized that the medicament has activated tissue regeneration considerably and reduced usual time and cost for classical treatment of decubitus scabs.

\section{INTRODUÇÃO}

Estes são resultados preliminares de uma pesquisa experimental realizada em pacientes portadores de escaras de decúbito, internados em um hospital de Belo Horizonte.

As escaras de decúbito têm sido, através dos tempos, uma grande preocupação de todos que lidam com pacientes acamados, há longo tempo. Estas feridas além do incômodo e da ameaça que representam para a saúde do doente, ainda são geradores de longas permanências nos hospitais, retardando o processo de tratamento fisioterápico dos pacientes e aumentando as despesas hospitalares, com seu cuidado.

Os métodos habitualmente utilizados em seu tratamento trazem algumas dificuldades por serem de alto custo ou anti-naturais.

$\mathrm{Na}$ tentativa de se encontrar uma alternativa para o tratamento de escaras de decúbito, propõe-se neste estudo experimentar o uso da Própolis, na concentração de $3 \%$, comparando-se os resultados com o método usual utilizado em pacientes internados no hospital onde está sendo feito o estudo.

Os objetivos do estudo são:

- Camparar o tempo gasto para granulação das escaras de decúbito em que se utilizou Fura- cim ou Iruxol com o tempo gasto para granulação daquelas em que se utilizou a Própolis.

- Verificar o valor bactericida da Própolis quando da sua utilização tópica em escaras de decúbito infectadas.

\section{LITERATURA}

\section{A Própolis - um dos produtos da abelha}

A Própolis é o produto resultante das resinas colhidas pelas abelhas dos troncos e brotos de árvores, às quais adicionam cera, polém e enzimas salivares. As abelhas colhedoras trazem as resinas nas corbículas (espécie de cestas com longos pelos, junto às patinhas traseiras) para as colméias onde são recebidas pelas abelhas que a mastigam outra vez enriquecendo-a com seus próprios componentes, principalmente as enzimas.

A Própolis tem um cheiro característico, agradável ao olfato, coloração esverdeada até o marrom, com consistência terrosa, pegajosa, dependendo de sua origem vegetal.

As abelhas utilizam a Própolis para as seguintes finalidades:

a) vedar as frestas e orifício das colmeias, diminuir a abertura de entrada e saída na col-

1. Enfermeira da Santa Casa de Misericórdia de Belo Horizonte.

2. Médico residente responsável pelo acompanhamento dos pacientes estudados na Santa Casa de Misericórdia.

3. Professor da U.F. Veterinária Belo Horizonte, responsável pelo estudo estatístico do trabalho. 
meia, impedindo a presença de inimigos e assegurando uma temperatura estável nas regiões frias, permitindo melhor isolamento térmico;

b) mumificação de cadáver de inimigos;

c) verniz para a superfície interna da colmeia;

d) revestimento de todos os favos, esterelizando o ambiente interno contra vírus e bactérias para a postura dos ovos;

e) reparar os favos estragados e consolidar os quadros móveis;

f) recobrir todas as superfícies dentro da colmeia, para que não fiquem ásperas.

A composição química da própolis é a seguinte: 50 a $55 \%$ resina e bálsamo. 5 a $10 \%$ de pólem, minerais, vitaminas, antibiótico e enzimas; $30 \%$ cera; $10 \%$ óleos voláteis.

De seus componentes, os mais importantes são os flavinóides seguindo-se os ácidos, álcoois, vitaminas e sais minerais. Os flavinóides são pigmentos amarelos obtidos de plantas com variadas proporções de Quercetina e Quercitrina. Os flavinóides reduzem a circulação das vias periféricas, agindo sobre as vias hemostáticas. A citrina em conjunto com a vitamina C tem alto valor terapêtico em relação ao escorbuto e aspereza das células sangüíneas. Alguns flavinóides potencializam enzimas, apresentando a capacidade anti-inflamatória dos tecidos, juntas ósseas, membranas, mucosas, protegendo a vitamina $\mathrm{C}$ contra oxidação, além de regular as funções do pâncreas. A Propolina, extrato da própolis, tem origem das flavinas ou flavinóideos. Foi constatado que a Propolina ativa o organismo quanto à formação de anticorpos, ativa a fagocitose e a formação de proteínas no sangue, além de ativar consideravelmente a regeneração do tecido. Sua ação antibiótica tem um espectro bastante largo, tanto bactericida como bacteriostático. A Propolina possui enzimas entre elas, Amilase, Catepsina, Lipase, Tripsina. As vitaminas A, B 1 , B 2 , B6, C, E, H, P são encontradas na Própolis. Nas cinzas de própolis foram encontrados: ferro, cobre, manganês, zinco, phutonzide, vitaminas do complexo $\mathrm{B}$, vitaminas $\mathrm{E}, \mathrm{C}, \mathrm{H}$ e vitamina $\mathrm{A}$, flavinóide, galantina, além de antibiótico e enzimas.

As abelhas segregam um antibiótico que as defende contra qualquer ataque de bactérias ou de vírus. Esta pesquisa feita pelo prof. Dr. Remy Chauvin comprovou que as abelhas segregam em todo corpo um antibiótico que mata as bactérias e vírus. Os antibióticos conhecidos perdem o seu ef eito com o tempo de uso, porque as bactérias e vírus se tornam resistentes a eles. Isto não se constata com os antibióticos segregados pelas abelhas. Os constituintes possuem um padrão de absorção, distribuição e excreção que assegura os níveis bactericidas pelo tempo necessário à cura.

Teoria de Kustemacher demonstra que as camadas externas do pólem contêm substâncias oleaginosas e balsâmicas inclusive resinas. As abelhas, ao separarem a parte digerível do pólem e as subs- tâncias balsâmicas resinosas, usam-nas em forma de própolis. A abelha acrescenta secreções salivares e cera à matéria resinosa bruta.

A própolis terá constituição diferente dependendo da matéria-prima vegetal que as abelhas usam na sua elaboração.

Sabe-se que a própolis já era usada pelos sacerdotes do Egito e pelos gregos, que deram origem a seu nome "Pro" significando diante e "polis", cidade - diante da cidade, por ser sempre encontrada na porta de entrada e saída das abelhas na colméia. Também foi usada pela civilização dos ricos contra infecções e, na África do Sul, na guerra dos boêres (1899-1902) foi empregada como cicatrizante.

Aristóteles considerava a própolis como "um remédio para os males da pele, as chagas e as supurações."

A própolis foi redescoberta em nossa era por vários pesquisadores que estudam suas verdadeiras propriedades e o real aproveitamento para a saúde do homem, sendo que na Europa (Bloco Soviético, França e Alemanha) têm sido feitas pesquisas com resultados surpreendentes em diversos tipos de doenças.

Estudos e/ou Pesquisas Realizadas

sobre a Própolis

1984 - Edward Henryk Szewczak e Geni Franco de Godoy (Szewczak \& Godoy 12 ) realizaram um estudo científico sobre a própolis. Fizeram um estudo comparativo entre a sensibilidade do Staphylococcus aureus à própolis e a antibiótico. Chegaram à conclusão de que a própolis exerce ação inibitória sobre as amostras de Stafilococcus aureus, os quais apresentam sensibilidade relevante à tintura nọ 1 ; e também de que os solventes empregados no preparo das tinturas de própolis não exercem ação inibidora sobre a bactéria em estudo; além do mais concluíram que a concentração mínima inibitória do Staphilococcus aureus à própolis era de $5,2 \%$ para $12,5 \mathrm{mg} / \mathrm{cm}^{3}(*)$.

1983 - TREVISAN13 (Pesquisador da Fundação Educacional de Barretos) realizou pesquisas com o emprego da própolis, utilizando somente própolis de colméia localizada em horto de eucaliptos, pois a mesma apresenta ausência de toxicidade, o que não acontece com a própolis obtida de outros vegetais.

1979 - VANHAELEN14 fez um estudo aprofundado sobre as origens, constituição química e atividade terapêutica sobre a própolis, chegando à conclsuão de que há uma atividade anti-bacteriana dos germes gram+ e gram-, anti-fungicida, tendo um efeito importante de regeneração dos tecidos além de uma ação anestésica acentuada. Atividade atuante sobre o Staphylococcus aureus, e epidermis, Bacillus subtilis, Bacillus alvei, Proteus vulgaris. Age com menor ação sobre a Salmonella e Escherischia coli B e sem nenhuma ação sobre outras Escherischia coli e Pseudomonas aeruginosas. "Os resultados diferem sempre uns dos outros: estas divergências provavel-

\footnotetext{
( *) Esses resultados publicados em 1984 são parciais, uma vez que o estudo ainda se encontra em andamento.
} 
mente são atribuídas à diferença de origem e as técnicas de recolhimento da própolis não padronizadas", diz o autor.

Outra conclusão a que se chegou: a própolis contém um antibiótico diferente daquele encontrado na abelha atuando sobre o Micobacterium Tuberculosis; apresenta também atividade antioxidante devido à presença de flavinóideos. O uso tópico da própolis em sua forma pastosa demonstrou ação cicatrizante, anti-inflamatório com resultados satisfatórios.

1978 - SHUB et alii11 fizeram estudo comparativo da atividade bactericida dos extratos alcoólicos de amostras de própolis de diferentes origens geográficas usando um único método. Para este estudo usaram Bacillus cereus, Staphylococccus aureus, Escherichia coli, Pseudomonas aeruginosa e Candida albicans. Constatou-se que a própolis tinha efeito antimicrobiano tanto no gram-positivo (Bac. cereus) quanto no gram-negativo. (Staph. aureus). Os outros três não sofreram o efeito da própolis. Chegou-se à conclusão de que a atividade bactericida da própolis depende da região em que foi coletada e da estandardização dos métodos empregados. Confirmou-se que ela possui propriedades anti-inflamatóris, renegerativas e anestésicas. Esta propriedade demonstra a importância do produto, propriedade esta ausente na maioria das drogas quimioterapêticas.

1964 - 1972 - DANILOV4, na Poli-Clínica da cidade de Svetogosk usou própolis em 680 enfermos com diferentes enfermidades da pele. Os resultados deste tratamento ofereceram a base para se emitir a hipótese de que "a Própolis possui propriedades terapêuticas determinadas, sendo possível o seu emprego no tratamento de pacientes com enfermidades da pele".

(S.D) - BOLSHAKOVA 2 relatou as pesquisas, no Instituto de Investigações Dermato-Venéreas da cidade de Gorki (U.R.S.S.), onde se emprega desde muito tempo, o produto à base de Própolis no tratamento de várias dermatoses com diferentes etiopatogênesis e particularidades clínicas (Hiperqueratoses, tuberculose da pele, alopecia, etc.). Os efeitos da administração da Própolis diferenciam-se segundo o aspecto clínico da enfermidade e rigorosidade no tratamento. Os resultados positivos do tratamento foram constatados em $82 \%$ dos enfermos; negativos em $18 \%$ dos pacientes com formas de enfermidades total ou subtotal e em nenhum dos casos tratados apareceram complicações do seu estado geral. Pode-se afirmar que a Própolis mostrou-se de utilidade na terapia das dermatoses específicas ainda que apareçam recidivas após o tratamento.

(S.D.) - DANILOV4 citou os resultados das investigações efetuadas por B. Tijonov e V. Balanikova com o tratamento de T.B.C da pele com própolis e por $G$. Mujamediarov no caso das eczemas crônicas e nervodermites, partindo daí um interesse no estudo da ação terapêutica da própolis no caso de algumas enfermidades da pele.

(S.D.) - ATIASOV relatou trabalhos feitos na U.R.S.S. aplicando-se própolis na forma de pomada em 830 pacientes de 17 meses a 87 anos de idade com queimaduras profundas, estendendo-se até $75 \%$ da superfície do corpo. Os resultados obtidos foram similares aos de KAZAKOV et alii em 1957; GLAGOLEVA, 1960; KIVALKINA, (1960) e KIRSANOV, 1965. Estes concluíram que a própolis tem ação bactericida nos microorganismos gram negativo e gram positivo, influência estimulativa no processo de regeneração das feridas intensificando a proliferação epitelial e o crescimento da granulação, melhorada circulação sangüínea e linfática, diminuição da permeabilidade de vasos da superfície da ferida.

Em outra pesquisa, o autor notou uma visível tendência de diminuição dos neutrófilos e de aumento numérico dos histrócitos, o que demonstra ativação do processo de regeneração das feridas. Notou também que a troca do curativo é menos dolorida não causando traumas nas granulações, o que é de suma importância na fase pós-enxerto de pele.

(S.D.) - VERGE7 (França) verificou a capacidade antibacteriana da própolis e encontrou resultados positivos em Bacillus subtillis, Alvei e Prodigiosus, assim como uma grande sensibilidade dos Stafilococus aureus e dourado e dos bacilos piogênicos. Ao contrário, não se evidencia ação alguma em toda uma série de Salmonella, uma série de Proteus e de Escherichia.

Os pesquisadores continuam buscando a dosagem e concentração ideal do produto para o organismo humano, embora os resultados obtidos, de modo geral, sejam satisfatórios, confirmando o grande valor terapêutico demonstrado nos estudos científicos.

\section{DESENVOL VIMENTO}

As características dos pacientes que são objeto deste estudo levaram à constatação da necessidade de agrupá-los em três subgrupos, para melhor controle das variáveis identificadas.

\section{POPULAÇÃO E AMOSTRA}

Determinou-se que fariam parte da população deste estudo todos os pacientes com escaras de decúbito internados no hospital em que se realiza a pesquisa. Destes pacientes, foram selecionados aqueles que apresentando diagnósticos variados, mostravam possibilidades de melhoras clínicas. Os demais pacientes que se encontravam em fase final não foram incluídos no estudo.

Entre os incluídos no estudo constavam indivíduos portadores das mais variadas patologias clínicas, com idade acima de 13 anos e estado nutricional e hidratação variáveis.

Para a constituição dos três subgrupos, foram considerados a faixa etária, o n? de escaras e sua distribuição no paciente. Naqueles pacientes em que as escaras localizavam-se em partes pares do corpo, isto é, no ombro direito e esquerdo, no calcâneo direito e esquerdo, deu-se o nome de escaras pareadas e estes pacientes foram considerados os seus próprios controles. Nestes, utilizou-se o método convencional para tratar aquelas escaras que se apresentavam em melhores condições e este grupo de escaras foi considerado o grupo controle. As escaras destes mesmos pacientes que demonstravam pior estado foram tratadas com Própolis.

Para avaliação do estado em que se encontravam as escaras no início do tratamento, elaborou- 
-se uma escala de conceitos de valor, que se referiu a: profundidade da ferida, presença ou não de tecido de granulação, de tecido necrosado, de secreção purulenta e extensão da escara.

Diante das características apresentadas pela ferida, atribuiu-se um conceito: Bom, Regular, Ruim e Péssimo.

Para as escaras que se encontravam superficialmente granuladas, com ausência de secreção e tecido necrótico, atribuiu-se o conceito Bom; deuse o conceito Regular para aquelas que se encontravam superficiais, com rasa ou média profundidade, granuladas, com ausência de secreção, e leve necrose. $\mathrm{O}$ conceito Ruim foi destinado àquelas escaras cuja presença de tecido necrótico era proporcionalmente maior que a anterior, além de apresentar pequena ou média quantidade de secreção purulenta. $\mathrm{E}$, por último, o conceito Péssimo, às escaras que apresentavam grande quantidade de secreção purulenta e com extensa ou média área de tecido necrótico.

\section{O Primeiro Grupo}

Fizeram parte do primeiro grupo os pacientes com idade entre 13 a 45 anos, independente de seu diagnóstico, e que apresentavam escaras pareadas.

$\mathrm{Na}$ maioria dos casos estes pacientes foram internados em conseqüência de acidentes de trabalho ou automobilístico que os levaram à paraplegia ou tetraplegia. As escaras foram em grande parte desenvolvidas em domicílio ou em hospitais. Seu aspecto era variável: com freqüência, já estavam infectadas, com grande quantidade de secreção purulenta e, às vezes, até com exposição óssea.

\section{O Segundo Grupo}

Constituíram este grupo de pacientes aqueles cuja faixa etária situava-se a partir de 46 anos. As patologias destes pacientes são na maioria seqüelas de A.V.C. ou outras neuropatias. Foram encontrados pacientes hemiplégicos, desnutridos, desidratados, apresentando escaras em membros pareados, adquiridas nos hospitais ou no domicílio. As escaras de decúbito estavam, na maioria infectadas, com grande quantidade de secreção purulenta, formando extensas "lojas" no tecido subcutâneo, com áreas ósseas expostas e necróticas.

\section{O Terceiro Grupo}

Este grupo foi composto de pacientes de todas as faixas etárias, que tinham todavia escaras isoladas, em sua maioria localizadas na região sacra. Estas se apresentavam com tecido necrótico, com muita secreção, provavelmente por ser uma área sujeita a constante contaminação por fezes. Não foram levadas em consideração as condições clínicas nem patológicas destes pacientes.

Para este grupo de pacientes, o objetivo diferia do anterior, que era o de comparar o tempo de cicatrização das feridas tratadas pela Própolis e por outras medicações. Neste grupo, o que se pretendia era verificar o efeito bactericida e bacteriostático da Própolis. Para tanto, foram realizados controles laboratoriais das secreções colhidas nas escaras.

\section{O Processo Utilizado}

Neste processo, o trabalho com os pacientes consiste de cinco etapas. Na primeira, feita semanalmente, identifica-se o paciente, portador de escaras, que responde à característica para inclusão na amostra ou seja, ter, pelo menos, prognóstico clínico regular.

$\mathrm{Na}$ segunda etapa, o paciente é examinado pela enfermeira pesquisadora, para determinar sua inclusão em um dos três grupos e para avaliar as escaras nele encontradas.

A terceira etapa diz respeito ao início do tratamento propriamente dito. Nesta etapa, os três grupos receberam as seguintes abordagens: no primeiro e segundo grupos, a enfermeira fez uma avaliação das escaras pareadas, identificando as de pior aspecto e aquelas que pareciam em melhores condições de recuperação. As escaras que mostravam com pior aspecto eram elegidas para receber o tratamento com Própolis e as demais tratadas com os métodos padronizados pelo hospital. As primeiras constituíam grupo experimental e as demais o controle, resultando em que, num mesmo paciente, encontrava-se os dois grupos de feridas. Para a terceira, realizou-se o seguinte processo: se a escara apresentasse secreção purulenta, esta era colhida e enviada ao laboratório para cultura. Em seguida, era iniciado o tratamento com Própolis.

A quarta etapa da tećnica consiste na visita médica para avaliação do tratamento e encaminhamento cirúrgico.

A quinta e última etapa diz respeito à cirurgia plástica corretiva.

Esre processo é sempre acompanhado com avaliação e registro diário da evolução do tratamento que é realizado pelas autoras.

A alta é dada em três situações:

19) Quando a escara se apresenta em condições cirúrgicas, ou seja, encontra-se totalmente granulada.

29) Quando ha cicatrização completa da ferida dispensando a cirurgia.

3Q) Quando as escaras estão regredidas porém o paciente obtém alța hospitalar ou morre em conseqüência de sua patologia.

\section{A Técnica de Cuidados das Escaras}

Para as "feridas controle", o curativo é feito com utilização de soro fisiológico para limpeza; em alguns casos, água oxigenada para limpeza da secreção e a seguir faz-se o debridamento, aplicando-se a pomada, ou gaze furacinada, e posteriomente, o curativo oclusivo.

No caso das feridas experimentais, faz-se a limpeza local com água destilada, em seguida, o debridamento, logo após o uso da pomada Própolis concentrada a $3 \%$, quando a escara está internamente visível. Quando as escaras se apresentam muito profundas, sem condições do uso da pomada, ou devido sua localização, introduz-se uma sonda uretral para limpeza com água destilada, injetando-se a seguir Própolis líquida na concentração mais baixa que a pomada. A seguir, coloca-se uma pequena gaze embebida com Própolis líquida na cavidade, tendo-se o cuidado de 
manter parte dessa gaze fora da cavidade. Após este processo, faz-se o curativo oclusivo.

Todo tratamento está sendo feito preferencialmente pelas autoras, ocorrendo em certas ocasiões a colaboração de algumas enfermeiras e funcionários.

\section{RESULTADOS PARCIAIS OBTIDOS NO ESTUDO}

A esta altura da pesquisa, já foram tratados 12 pacientes que apresentaram um total de 19 escaras tratadas com própolis e 15 com o método padronizado pelo hospital. Espera-se tratar 76 pacientes, para se conseguir uma amostra significativa para $o$ estudo.

\section{CONCLUSÃO}

Embora o estudo esteja em fase inicial de seu desenvolvimento, já se podem verificar vantagens significativas na evolução do tratamento das escaras de decúbito com o uso da própolis. Estas vantagens dizem respeito à maior rapidez na regeneração da área ferida, ao baixo custo do produto em relação aos habitualmente utilizados e ao fato da própolis constituir um produto natural com possibildades muito menores de provocar reações indesejáveis a paciente.

AZEVEDO, I.B.S. et alii. Treatment of decubitus scabs with Própolis. Rev. Bras. Enf., Brasília, 39(2/3): 33-37, Apr./Sept., 1986.

\section{REFERENCIAS BIBLIOGRAFICAS}

1. ATIASOV, N.I. et alii. Empleo del ungüento con propoleos en el tratamiento de las llagas en estado de granulación: experiencia de un decenio del Hospital Ruso para tratar las quemaduras. s.l.p., Apicenter do Brasil, s.d. Apostila.

2. BOLSHAKOVA, V.F. Emprego da própolis em dermatologia s.l.p., Apicenter do Brasil, s.d. Apostila.

3. BREYER, E. U. Abelhas e saúde. 4 ed. Porto União, Santa Catarina, Uniporto, 1984.

4. DANILOV, L.N. Tratamento com própolis de algumas enfermidades da pele. s.l.p., Apicenter do Brasil, s.d. Apostila.

5. KLEINROK, Z. et alii. Biological properties and clinical application of Propolis. Arzneimittel - Forschung, Aulendorf, Wurttemberg, 29 (2): 291-2.

6. KLIMMEK. E. Curta consideração sobre Própolis. In: GOMES, I.C. Própolis, o antibiótico natural. Saúde Especial. s.n.t.

7. LAVIE, P. El antibiotic del propoleos. s.l.p., Apicenter do Brasil, s.d. Apostila.

8. SCHELLER, S. et alii. Estudio comparativo de los stafilococos al propoleos y a los antibióticos. s.l.p., Apicenter do Brasil, s.d. Apostila.

9. Biological properties and clinical application of propolis. Arzneimittel-Forshung, Aulendorf, Wurttemberg. 28(9): 1954-5, 1978.

10. SCHMIDT, F.W.U. \& LARA, F.J.M. Técnica e prática de apicultura. Belo Horizonte, Edição dos Autores, 1985. Apostila.

11. SHUB. T.A et alii. Antimicrobial activity of Propolis extracts. Pharm. Chem. J., 11 (9): 1242-4, 1978.

12. SZEWCZAK, E. H. \& GODOY, G.F. Um estudo científico sobre própolis. A picultura no Brasil, s.n.t.

13. TREVISAN. M.D.P. Própolis. Inf. Agropecuário, Belo Horizonte, 9 (106): 50-2, out. 1983.

14. VANhaELEN, M. et alii. Própolis II identification parchomatographies haute-performance (liquide, gaz-liquide et sur couches minces) des Constituants. Bioautographie des chromato - grammes des composés antibacteriens. J. Pharm. Belgique, Bruxelles, 34 (6): 317-28, 1979. 